\title{
Decision-Making in the Surgical Treatment of Breast Cancer: Factors Influencing Women's Choices for Mastectomy and Breast Conserving Surgery
}

\author{
Emily Catherine Bellavance* and Susan Beth Kesmodel
}

Department of General and Oncologic Surgery, University of Maryland, Baltimore, MD, USA

One of the most difficult decisions a woman can be faced with when choosing breast cancer treatment is whether or not to undergo breast conserving surgery or mastectomy. The factors that influence these treatment decisions are complex and involve issues regarding access to health care, concerns for cancer recurrence, and the impact of surgery on body image and sexuality. Understanding these factors will help practitioners

OPEN ACCESS

Edited by:

Sarah M. Temkin,

National Cancer Institute, USA

Reviewed by:

Anees Chagpar,

Yale School of Medicine, USA

Alexandra Resch,

Medical University Vienna, Austria

*Correspondence:

Emily Catherine Bellavance ebellavance@smail.umaryland.edu

Specialty section:

This article was submitted to

Women's Cancer,

a section of the journal

Frontiers in Oncology

Received: 11 January 2016

Accepted: 14 March 2016

Published: 29 March 2016

Citation:

Bellavance EC and Kesmodel SB

(2016) Decision-Making in the Surgical Treatment of Breast Cancer:

Factors Influencing Women's Choices for Mastectomy and Breast

Conserving Surgery.

Front. Oncol. 6:74.

doi: 10.3389/fonc.2016.00074 to improve patient education and to better guide patients through this decision-making process. Although significant scientific and societal advances have been made in improving women's choices for the breast cancer treatment, there are still deficits in the decision-making processes surrounding the surgical treatment of breast cancer. Further research is needed to define optimal patient education and shared decision-making practices in this area.

Keywords: mastectomy, breast cancer, breast conserving surgery, shared decision-making, contralateral prophylactic mastectomy

\section{INTRODUCTION}

Medical decision-making has evolved over the last several decades from one based on paternalism, in which the physician decided on the best course of treatment according to his/her view of what was in the best interest of the patient, to one focused on patient autonomy, in which the informed patient makes decisions about accepting or declining treatment options based on his/her own values and priorities. In modern medical ethics, shared decision-making has been proposed as the ideal model for medical decision-making that both acknowledges patient autonomy and the role of the physician in providing expert medial opinion. Shared decision-making is a process that informs patients about what available treatments are most effective under particular circumstances, incorporates patients' needs and values into decisions, and improves the patient-clinician dialog about decisions $(1,2)$. Shared decision-making has been advocated as an ideal model to address treatment decisions in which no single treatment option is clearly indicated above others based on available medical evidence (2). Therefore, this model is particularly suited to treatment decisions in the management of the primary tumor in breast cancer, as a patient may face several surgical treatment options that result in equivalent oncologic outcomes.

One of the most difficult decisions a woman can be faced with when choosing breast cancer treatment is whether or not to undergo breast conserving surgery (BCS) or mastectomy. Notably, the 
clinical research in breast cancer treatment, which supports the use of BCS, came about at the time when women were also becoming dissatisfied with the traditional paternalistic doctor-patient relationship model and were demanding to have more choice in their medical care. In his book, "The Breast Cancer Wars," Barron Lerner chronicles the convergence of the women's liberation movement and the rise of BCS as the standard of surgical care in the treatment of early stage disease (3). In 1971, the writer Babette Rosamond was diagnosed with breast cancer when one of the first proponents of BCS, Bernard Crile, was offering a partial mastectomy as opposed to the traditional one-step procedure in which a woman with a suspicious breast mass was consented for an excisional biopsy under anesthesia and if this mass was determined to be a cancer on frozen section, the surgeon would then proceed with a radical mastectomy, which included the removal of the breast, overlying skin, axillary lymph nodes, and pectoralis muscles. When Babette Rosamond was presented with the one-step procedure, she refused and only gave permission for the excisional biopsy. The excision demonstrated a small focus of breast cancer. She then refused the radical mastectomy and sought out the opinion of Dr. Crile at the Cleveland Clinic who cited data from retrospective studies of less aggressive surgery, resulting in acceptable outcomes. Ms. Rosamond wrote about her experience in an article, "The Right to Choose," in the popular woman's journal McCall's Magazine and ultimately published a book entitled, “The Invisible Worm." She joined a host of other women leaders of the time who were vocal proponents against the current medical establishment's support of aggressive breast cancer surgery who demanded choice in their cancer care and the option of less aggressive and more cosmetic procedures.

Concurrently, in the late 1960s, the surgeon Bernard Fisher developed and promoted a biological model of breast cancer in which he proposed that breast cancer was a systemic disease requiring both local and systemic treatment (4). Therefore, more radical surgery was not necessarily beneficial in the face of disseminated tumor cells. Although commending Crile and others for pursuing BCS, Fisher demanded more rigorous evidence to support less aggressive surgery by means of randomized clinical trials. Under his leadership, the National Surgical Adjuvant Breast and Bowel Project (NSABP) B04 and B06 trials were conducted. The NSABP-B04 trial demonstrated that sparing the pectoralis muscles in mastectomy did not negatively affect oncologic outcomes (5). The NSABP-B06 trial established that BCS results in equivalent overall survival as mastectomy in patients with early stage breast cancer (6). The addition of adjuvant radiation treatment to BCS decreased the rate of local recurrence from 39 to $14 \%$ over 20 years. To date, there are multiple randomized clinical trials with long-term follow-up demonstrating no difference in overall survival between BCS with adjuvant radiation and mastectomy for the treatment of operable breast cancers (6-11). Refinement of radiation techniques and the addition of adjuvant systemic therapies have further decreased the rate of local recurrence in BCS to approach that of mastectomy $(12,13)$. Currently, one of the quality assurance standards for the National Accreditation Program for Breast Centers in the United States is that at least $50 \%$ of Stages 1-2 breast cancers amenable to BCS are treated with partial mastectomy.

\section{MASTECTOMY AND BREAST CONSERVATION}

Despite data supporting BCS in eligible patients, a significant percentage of women who would be candidates for BCS still decide to undergo mastectomy. The factors that influence these treatment decisions are complex and involve issues regarding access to health care, concerns for cancer recurrence, and the impact of surgery on body image and sexuality. Understanding these factors will help practitioners to improve patient education and to better guide patients through this decision-making process.

Access to health care is one of the major determinants of choice for breast cancer surgery, especially with regard to access to specialty providers and treatment facilities. Because adjuvant radiation therapy is usually recommended after BCS, multiple studies have focused on the availability of radiation oncology specialists. A recent publication using data from the surveillance, epidemiology, and end results (SEER) database and the Health Resources and Services Administration Area Resource File evaluated the association between the choice of breast surgery (mastectomy or BCS), the receipt of adjuvant radiation therapy after BCS, and the density of radiation oncologists in a particular area (ROD) (14). The study demonstrated that the likelihood of a woman undergoing BCS for early stage breast cancer increased as the ROD in an area increased. In addition, the likelihood that adjuvant radiation therapy was omitted after BCS decreased as the ROD in an area increased. The results from this study are consistent with those of a large study using the Medicare database that evaluated the use of BCS in older breast cancer patients and demonstrated that BCS was used more frequently in counties with a high density of radiation oncologists (15).

Numerous studies have also demonstrated that travel distance for radiation therapy may be associated with decisions regarding BCS and the actual delivery of adjuvant radiation therapy after BCS (16-21). The largest of these studies evaluated the use of BCS in women with early stage breast cancer using the SEER database (17). This study showed that the use of BCS was more common when women received treatment in a hospital with a radiation facility compared to women living a greater distance from a hospital with a radiation center. This was statistically significant for women who resided $\geq 15$ miles from the nearest hospital with a radiation treatment center (OR $0.52,95 \%$ CI $0.46-0.58$ ). The study also demonstrated that for women who had BCS, a statistically significant decrease in the use of adjuvant radiation therapy was observed in patients who lived $\geq 40$ miles from a hospital with a radiation facility, although this only accounted for $1.7 \%$ of the patients in the study. The use of accelerated radiation schedules, including shorter course whole breast irradiation given over 3 weeks and partial breast irradiation, may help to ameliorate some of these issues by providing patients with more manageable radiation schedules.

The use of multidisciplinary treatment teams is becoming more common in the management of breast cancer patients, especially at larger, academic institutions where breast cancer specialists are available in multiple disciplines. However, a significant percentage of patients still do not have the opportunity to meet with a medical oncologist or radiation oncologist before undergoing 
surgery for breast cancer. One of the benefits of a multidisciplinary approach is that patients understand all the components of their breast cancer treatment prior to starting treatment, and this increased knowledge may have an impact on treatment decisions regarding surgery for breast cancer. In a study of elderly women aged $\geq 65$ years with local or regional breast cancer treated from 1994 to 1995 , those patients who had a consultation with a radiation oncologist preoperatively were 6.7 times more likely to have BCS compared to those who did not $(P \leq 0.001)$. Furthermore, the odds of a patient receiving adjuvant radiation therapy after BCS were five times greater for patients who had a preoperative radiation oncology consultation $(P<0.001)$. Although this study was conducted at the time when multidisciplinary care was not as prevalent as it is today, it did demonstrate how multidisciplinary care may influence treatment choices (22). Several studies have demonstrated that surgeon characteristics including practice setting and gender have an impact on BCS rates (23-25). Surgeons who are affiliated with academic institutions, whether or not they have fellowship training in breast surgery or surgical oncology, use BCS more often than community surgeons (23). This may be due to the greater availability of other specialty providers at academic institutions and the use of multidisciplinary care in this setting. The number and availability of reconstructive surgeons at a particular institution have also been shown to impact rates of mastectomy and reconstruction and BCS (19). In an analysis of patients treated for breast cancer at National Comprehensive Cancer Network institutions, a greater number of reconstructive surgeons were associated with increased mastectomy and reconstruction rates, whereas long wait times for breast reconstructive surgery were associated with increased BCS rates.

Factors predicting the use of BCS, including clinicopathologic, socioeconomic, and patient characteristics, have been examined in numerous studies. Tumor characteristics, including tumor size, lymph node involvement, and stage, have all been shown to influence treatment decisions, with BCS used more frequently in patients with smaller tumors $(23,26)$ without lymph node involvement (15) and mastectomy used more often in patients with higher stage (27). Socioeconomic factors, including higher education, low poverty areas, and private insurance, are also associated with increased use of BCS $(15,21,24)$. Significant geographic variation also exists in the use of BCS, both local and regional. Multiple studies have demonstrated that patients living in the Northeast and Pacific West are more likely to have BCS than those in the South (15, $23,26,28)$. In an analysis of older breast cancer patients, $70 \%$ of the patients in the Northeast had BCS compared to $48-50 \%$ of patients in the South $(P<0.001)(15)$. In this study, patients in metropolitan areas were also more likely to have BCS than patients in rural areas. This may simply reflect decreased access to health care and particularly breast cancer specialists. This geographic variation may also be influenced by other factors, including education and socioeconomic status.

Although some single institution studies have shown that younger patient age is associated with the use of BCS $(15,21,23,24)$, more recent analysis of large national databases suggest that this trend has reversed. Two reviews of the National Cancer Database have demonstrated in the setting of an overall increase of BCS, younger patients are being treated with mastectomy at higher rates than their older counterparts after adjusting for patient, facility, and tumor characteristics $(28,29)$. The subset of women aged $\leq 35$ years was twice as likely to undergo mastectomy compared to women aged 61-64 years (29). These studies also reported similar trends with socioeconomic status, geography, and cancer stage outlined above, with a more recent narrowing of the BCS disparity in the South (28). In addition, access to radiation also appeared to influence BCS rates in these studies. It is unclear why younger women may be opting for more extensive surgery. This may be due to a concern for locoregional recurrence in younger patients (30), although more aggressive surgery does not appear to affect breast cancer-specific survival (31). Increased awareness of familial breast cancer syndromes may also be affecting mastectomy rates in younger women, who are at higher risk for having a deleterious genetic mutation and therefore may be choosing bilateral mastectomy for the treatment of a unilateral cancer.

When patients are diagnosed with breast cancer, they obtain support and advice from multiple sources when making decisions regarding breast surgery. The surgeon's recommendation or preference for care is frequently cited as an important factor in this decision-making process. In a survey study that examined breast cancer care in a group of 96 patients, women who chose BCS indicated that the most important factor in the decision was the surgeon (32). This was in contrast to patients who selected mastectomy with or without reconstruction, where fear of cancer and concern about radiation therapy were ranked as more significant factors.

One of the major goals for providers is to help patients make informed decisions about their care. The development and use of decision-making aids have been investigated by several groups as a way to help providers obtain a better understanding of patient preferences for treatment $(33,34)$. These aids may also enhance patient decision-making by improving delivery of information and facilitating communication between providers and patients. In one study, patients and surgeons were interviewed to identify key factors influencing breast cancer surgery decisions, which were then incorporated into a decision board that could be reviewed at the time of surgical consultation (34). For patients, information on options for reconstruction, quality of life, and body image was important factors, whereas for surgeons, details regarding treatment side effects were considered important. The decision board was administered to 175 patients and $98 \%$ reported that it was easy to understand and $81 \%$ indicated that it helped in the decision process. Surgeons also found the decision board to be helpful in presenting information to patients. A subsequent randomized trial comparing the decision board to usual care demonstrated that patients who had surgical consultations with the decision board had higher knowledge scores regarding treatment options (66.9 vs. 58.7, $P<0.0001$ ), less decisional conflict ( 1.40 vs. $1.62, P=0.02)$, and were more satisfied with the decision-making process ( 4.50 vs. $4.32, P=0.05)$. In addition, patients in the decision board group were more likely to undergo BCS (94 vs. $76 \%, P=0.03$ ). A similar approach using an interactive $\mathrm{CD}-\mathrm{ROM}$ decision aid showed that patients using the CD-ROM were more satisfied with the amount of information received, their treatment decisions, and the decision-making 
process (33). However, the CD-ROM decision aid had no impact on treatment decisions. A recent meta-analysis of studies using decision aids in breast cancer patients, which included the above studies, demonstrated that in the three randomized trials of decision aids, women were $25 \%$ more likely to choose BCS over mastectomy if a decision aid was utilized (risk ratio 1.25, 95\% CI 1.11-1.40) (35). In addition, decision aids increased patient knowledge by $24 \%$, decreased decisional conflict, and improved the overall decision-making process.

\section{BODY IMAGE AND BREAST RECONSTRUCTION}

An important concern for women undergoing breast cancer surgery is the impact this will have on body image and sexuality. Some studies have demonstrated that women undergoing BCS have fewer concerns about body image compared to mastectomy patients (36-39), whereas others have found no difference between the BCS and mastectomy groups $(40,41)$. In a recent meta-analysis of 12 studies on body image after breast cancer surgery, Fang et al. demonstrated that BCS patients had a better overall body image than women undergoing mastectomy with reconstruction and scored higher on body stigma domain (42). However, reconstruction significantly improved body image in mastectomy patients compared to no reconstruction. In addition, cosmetic satisfaction in postmastectomy patients with reconstruction appears to be high $(43,44)$. Currently, in the United States, universal coverage for postmastectomy reconstruction is mandated based on the passing of the Women's Health and Cancer Rights Act in 1998. Despite the majority of patients do not undergo reconstruction (19). Factors associated with not receiving postmastectomy reconstruction include social and racial disparities, including black race, lower educational level and income, and public insurance (45-48). Although the racial disparity with breast reconstruction has been shown in multiple studies, a review of the Department of Defense cancer database shows that the receipt of reconstruction between White and Black women was equivalent, suggesting that the racial disparity with reconstruction may not be as evident when access is equal (49). Other factors associated with low reconstruction rates include older patient age, advanced disease, presence of comorbidities, and lack of access to reconstructive surgeons (19, 45-47). Although exogenous factors influencing reconstruction rates can be identified by institutional and database reviews, few studies have examined patients' perspective of decision-making about breast reconstruction. In a survey study of breast cancer patients sampled from the SEER database, the majority of mastectomy patients reported satisfaction with the decision-making process about reconstruction. Dissatisfaction was associated with race, with black and Latina women being less satisfied, but was not associated with income or educational level. The most common reasons cited by patients for not undergoing reconstructive surgery are to avoid additional surgery and that they did not feel reconstruction was important. The main systems barrier reported to obtain reconstruction was lack of insurance coverage, whereas knowledge of the reconstruction as an option and finding a reconstructive surgeon were not significant barriers (45).

\section{CONTRALATERAL PROPHYLACTIC MASTECTOMY}

Contralateral prophylactic mastectomy (CPM) is the removal of the healthy breast in the treatment of a unilateral cancer. Reviews of large national databases in the United States have demonstrated an increase in the rates of CPM in cases of operable breast cancer by over $150 \%(50,51)$. This trend has also been reproduced in multiple single institution studies, with centers reporting CPM rates as high as $24 \%$ in the treatment of mastectomy patients $(52,53)$. These data are notable for the finding that patient factors are often more powerful predictors than tumor factors. Specifically, White race, higher socioeconomic status, and young age have been consistently identified as independent predictors for $\mathrm{CPM}(50,52,53)$. Despite the increasing frequency of CPM in the treatment of breast cancer, the oncologic benefit of this procedure is controversial in patients who do not have a genetic predisposition in developing breast cancer. Although CPM does reduce the risk of developing a contralateral breast cancer significantly, the incidence of contralateral cancers is low and has been declining over time due to advances in adjuvant chemotherapy and endocrine therapy (54). Currently, the incidence of contralateral breast cancer in patients can be estimated based on large retrospective cohort reviews and ranges from 0.3 to $1 \%$ per year depending on the age of diagnosis and characteristics of the primary tumor (54-56). The data on survival benefit of CPM are contradictory. Retrospective studies comparing unilateral mastectomy with CPM have demonstrated disease specific and overall survival benefit $(57,58)$. However, more recent data suggest that there is no difference in survival when breast conservation is compared with CPM (59). A recent meta-analysis conducted by Cochran Collaboration concluded that there was insufficient evidence to demonstrate a survival benefit with CPM (60).

Data on patients' motivations for choosing CPM indicate that the patient's choice for CPM appears to be dominated by a fear of developing another breast cancer, whereas the risk of a contralateral breast cancer and disease-specific death is routinely overestimated by patients (61-64). In a prospective survey of newly diagnosed breast cancer patients, Abbott et al. found that the mean estimated risk by patients for developing a contralateral cancer was $31 \%$ over 10 years, about ninefold the expected risk of most breast cancer patients. The perceived risk was not associated with stage, family history of breast cancer, or age of diagnosis (61). Similarly, in a qualitative study consisting of interviews with mastectomy and CPM patients, Covelli et al. noted that patients estimated a high, almost inevitable, risk of cancer recurrence and contralateral breast cancer development that they translated into a high risk of breast cancer-related death. Patients who chose CPM feared developing a contralateral cancer and the prospect of undergoing breast cancer treatment again at some point in the future (64). These results are similar to survey studies demonstrating that the most common reasons women report for choosing $\mathrm{CPM}$ are to avoid the development of a contralateral cancer and 
to improve their survival $(61,63)$. Other common reasons women choose CPM in these surveys were to achieve a symmetric cosmetic result, to avoid future tests and breast cancer surveillance, and to allay concern that future screening would not identify a new cancer. Given the apparent discordance between patients' anticipated benefits of CPM and the expected oncologic benefit expected, many clinicians have called for improving communication practices and patient education in this area. Currently, the use of decision aids is being investigated as a tool to help clinicians and patients navigate decision-making in CPM $(63,65)$.

Although breast cancers secondary to a hereditary syndrome are uncommon, it is important to recognize that there is a population of women who do have a high risk of developing a contralateral cancer and therefore may benefit from CPM. Women with a deleterious BRCA mutation can have up to a $40 \%$ risk of developing a contralateral breast cancer over 10 years (66-68). CPM may also provide a survival benefit in deleterious BRCA mutation carriers $(66,69)$. Furthermore, patients with a strong family history without an identifiable genetic mutation appear to be at increased risk of developing a contralateral cancer, depending on age of diagnosis, whether the relative had a bilateral or unilateral cancer, and the degree of relative with breast cancer (first or second degree relative) (70). Genetic testing in breast cancer has also expanded to include next generation cancer panels in addition to testing for BRCA mutations. Panel testing may be appropriate for women with a strong family history without a BRCA mutation or those who have a family history indicative for more than one hereditary cancer syndrome. Unfortunately, the addition of expanded genetic testing is not without risk. Patients are more likely to test positive for a genetic variant of uncertain significance, which can make the decision-making process about prophylactic surgery even more confusing (71). Additionally, data

\section{REFERENCES}

1. Politi MC, Studts JL, Hayslip JW. Shared decision making in oncology practice: what do oncologists need to know? Oncologist (2012) 17(1):91-100. doi:10.1634/theoncologist.2011-0261

2. Pope TM, Hexum M. Legal briefing: shared decision making and patient decision aids. J Clin Ethics (2013) 24(1):70-80.

3. Lerner B. The Breast Cancer Wars. New York, NY: Oxford University Press (2001).

4. Fisher B. Laboratory and clinical research in breast cancer - a personal adventure: the David A. Karnofsky memorial lecture. Cancer Res (1980) 40(11):3863-74.

5. Fisher B, Jeong JH, Anderson S, Bryant J, Fisher ER, Wolmark N. Twentyfive-year follow-up of a randomized trial comparing radical mastectomy, total mastectomy, and total mastectomy followed by irradiation. $N$ Engl J Med (2002) 347(8):567-75. doi:10.1056/NEJMoa020128

6. Fisher B, Anderson S, Bryant J, Margolese RG, Deutsch M, Fisher ER, et al. Twenty-year follow-up of a randomized trial comparing total mastectomy, lumpectomy, and lumpectomy plus irradiation for the treatment of invasive breast cancer. N Engl J Med (2002) 347(16):1233-41. doi:10.1056/ NEJMoa022152

7. Clarke M, Collins R, Darby S, Davies C, Elphinstone P, Evans V, et al. Effects of radiotherapy and of differences in the extent of surgery for early breast cancer on local recurrence and 15-year survival: an overview of the randomised trials. Lancet (2005) 366(9503):2087-106. doi:10.1016/S0140-6736(05)67887-7

8. Simone NL, Dan T, Shih J, Smith SL, Sciuto L, Lita E, et al. Twenty-five year results of the national cancer institute randomized breast conservation trial. Breast Cancer Res $\operatorname{Tr}$ (2012) 132(1):197-203. doi:10.1007/s10549-011-1867-6 on risk stratification for other mutations are often not as mature as the BRCA data on cancer risk, and thus even in the setting of a deleterious mutation, it is difficult to quote accurate risk to the patient. Therefore, it is important for women undergoing genetic testing to also be formally counseled on the significance of the results by a specialist trained in genetic counseling.

\section{CONCLUSION}

Choosing between mastectomy and BCS can be a difficult decision involving personal preferences about body image and sexuality. In addition, external factors can influence this choice, including socioeconomic status and access to adjuvant radiation therapy, surveillance imaging, and reconstructive surgeons. Although national rates of BCS for early stage breast cancers are on the rise, rates of mastectomy have increased in young patients for reasons that are unclear. Furthermore, bilateral mastectomy has also become a common procedure in the treatment of a unilateral cancer. Most breast cancer patients are at a very low risk for developing a contralateral cancer, and yet the choice for CPM appears to be motivated by fear of developing a new cancer in the healthy breast. Although significant scientific and societal advances have been made in improving women's choices for the breast cancer treatment, there are still deficits in the decision-making processes surrounding the surgical treatment of breast cancer. Further research is needed to define optimal patient education and shared decision-making practices in this area.

\section{AUTHOR CONTRIBUTIONS}

Both authors contributed to the writing and final approval of the manuscript.

9. Arriagada R, Le MG, Rochard F, Contesso G. Conservative treatment versus mastectomy in early breast cancer: patterns of failure with 15 years of follow-up data. Institut Gustave-Roussy Breast Cancer Group. J Clin Oncol (1996) 14(5):1558-64.

10. Veronesi U, Cascinelli N, Mariani L, Greco M, Saccozzi R, Luini A, et al. Twenty-year follow-up of a randomized study comparing breast-conserving surgery with radical mastectomy for early breast cancer. N Engl J Med (2002) 347(16):1227-32. doi:10.1056/NEJMoa020989

11. Litiere S, Werutsky G, Fentiman IS, Rutgers E, Christiaens MR, Van Limbergen $\mathrm{E}$, et al. Breast conserving therapy versus mastectomy for stage I-II breast cancer: 20 year follow-up of the EORTC 10801 phase 3 randomised trial. Lancet Oncol (2012) 13(4):412-9. doi:10.1016/S1470-2045(12)70042-6

12. Bartelink H, Horiot JC, Poortmans P, Struikmans H, Van den Bogaert W, Barillot I, et al. Recurrence rates after treatment of breast cancer with standard radiotherapy with or without additional radiation. N Engl J Med (2001) 345(19):1378-87. doi:10.1056/NEJMoa010874

13. Vaidya JS, Wenz F, Bulsara M, Tobias JS, Joseph D, Baum M. Radiotherapy for breast cancer, the TARGIT-A trial - authors' reply. Lancet (2014) 383(9930):1719-20. doi:10.1016/S0140-6736(14)60830-8

14. Churilla TM, Donnelly PE, Leatherman ER, Adonizio CS, Peters CA. Total mastectomy or breast conservation therapy? How radiation oncologist accessibility determines treatment choice and quality: a SEER data-base analysis. Breast J (2015) 21(5):473-80. doi:10.1111/tbj.12449

15. Smith GL, Xu Y, Shih YC, Giordano SH, Smith BD, Hunt KK, et al. Breast-conserving surgery in older patients with invasive breast cancer: current patterns of treatment across the United States. J Am Coll Surg (2009) 209(4):425-33.e2. doi:10.1016/j.jamcollsurg.2009.06.363 
16. Voti L, Richardson LC, Reis IM, Fleming LE, Mackinnon J, Coebergh JW. Treatment of local breast carcinoma in Florida: the role of the distance to radiation therapy facilities. Cancer (2006) 106(1):201-7. doi:10.1002/ cncr. 21557

17. Nattinger AB, Kneusel RT, Hoffmann RG, Gilligan MA. Relationship of distance from a radiotherapy facility and initial breast cancer treatment. J Natl Cancer Inst (2001) 93(17):1344-6. doi:10.1093/jnci/93.17.1344

18. Athas WF, Adams-Cameron M, Hunt WC, Amir-Fazli A, Key CR. Travel distance to radiation therapy and receipt of radiotherapy following breastconserving surgery. J Natl Cancer Inst (2000) 92(3):269-71. doi:10.1093/ jnci/92.3.269

19. Greenberg CC, Lipsitz SR, Hughes ME, Edge SB, Theriault R, Wilson JL, et al. Institutional variation in the surgical treatment of breast cancer: a study of the NCCN. Ann Surg (2011) 254(2):339-45. doi:10.1097/SLA.0b013e3182263bb0

20. Dragun AE, Huang B, Tucker TC, Spanos WJ. Disparities in the application of adjuvant radiotherapy after breast-conserving surgery for early stage breast cancer: impact on overall survival. Cancer (2011) 117(12):2590-8. doi:10.1002/cncr.25821

21. Onega T, Cook A, Kirlin B, Shi X, Alford-Teaster J, Tuzzio L, et al. The influence of travel time on breast cancer characteristics, receipt of primary therapy, and surveillance mammography. Breast Cancer Res Treat (2011) 129(1):269-75. doi:10.1007/s10549-011-1549-4

22. Baldwin LM, Taplin SH, Friedman H, Moe R. Access to multidisciplinary cancer care: is it linked to the use of breast-conserving surgery with radiation for early-stage breast carcinoma? Cancer (2004) 100(4):701-9. doi:10.1002/ cncr.20030

23. Chagpar AB, Studts JL, Scoggins CR, Martin RC II, Carlson DJ, Laidley AL, et al. Factors associated with surgical options for breast carcinoma. Cancer (2006) 106(7):1462-6. doi:10.1002/cncr.21728

24. Cyran EM, Crane LA, Palmer L. Physician sex and other factors associated with type of breast cancer surgery in older women. Arch Surg (2001) 136(2):185-91. doi:10.1001/archsurg.136.2.185

25. Gilligan MA, Neuner J, Sparapani R, Laud PW, Nattinger AB. Surgeon characteristics and variations in treatment for early-stage breast cancer. Arch Surg (2007) 142(1):17-22. doi:10.1001/archsurg.142.1.17

26. Morrow M, White J, Moughan J, Owen J, Pajack T, Sylvester J, et al. Factors predicting the use of breast-conserving therapy in stage I and II breast carcinoma. J Clin Oncol (2001) 19(8):2254-62.

27. Staradub VL, Hsieh YC, Clauson J, Langerman A, Rademaker AW, Morrow M. Factors that influence surgical choices in women with breast carcinoma. Cancer (2002) 95(6):1185-90. doi:10.1002/cncr.10824

28. Lautner M, Lin H, Shen Y, Parker C, Kuerer H, Shaitelman S, et al. Disparities in the use of breast-conserving therapy among patients with early-stage breast cancer. JAMA Surg (2015) 150(8):778-86. doi:10.1001/jamasurg.2015.1102

29. Freedman RA, Virgo KS, Labadie J, He Y, Partridge AH, Keating NL. Receipt of locoregional therapy among young women with breast cancer. Breast Cancer Res Treat (2012) 135(3):893-906. doi:10.1007/s10549-012-2156-8

30. Cao JQ, Olson RA, Tyldesley SK. Comparison of recurrence and survival rates after breast-conserving therapy and mastectomy in young women with breast cancer. Curr Oncol (2013) 20(6):e593-601. doi:10.3747/co.20.1543

31. Ye JC, Yan W, Christos PJ, Nori D, Ravi A. Equivalent survival with mastectomy or breast-conserving surgery plus radiation in young women aged $<40$ years with early-stage breast cancer: a national registry-based stageby-stage comparison. Clin Breast Cancer (2015) 15(5):390-7. doi:10.1016/j. clbc.2015.03.012

32. Nold RJ, Beamer RL, Helmer SD, McBoyle MF. Factors influencing a woman's choice to undergo breast-conserving surgery versus modified radical mastectomy. Am J Surg (2000) 180(6):413-8. doi:10.1016/S0002-9610(00)00501-8

33. Molenaar S, Sprangers MA, Rutgers EJ, Luiten EJ, Mulder J, Bossuyt PM, et al. Decision support for patients with early-stage breast cancer: effects of an interactive breast cancer $\mathrm{CDROM}$ on treatment decision, satisfaction, and quality of life. J Clin Oncol (2001) 19(6):1676-87.

34. Whelan T, Levine M, Gafni A, Sanders K, Willan A, Mirsky D, et al. Mastectomy or lumpectomy? Helping women make informed choices. J Clin Oncol (1999) 17(6):1727-35.

35. Waljee JF, Hawley S, Alderman AK, Morrow M, Katz SJ. Patient satisfaction with treatment of breast cancer: does surgeon specialization matter? J Clin Oncol (2007) 25(24):3694-8. doi:10.1200/JCO.2007.10.9272
36. Ganz PA, Schag AC, Lee JJ, Polinsky ML, Tan SJ. Breast conservation versus mastectomy. Is there a difference in psychological adjustment or quality of life in the year after surgery? Cancer (1992) 69(7):1729-38. doi:10.1002/10970142(19920401)69:7<1729::AID-CNCR2820690714>3.0.CO;2-D

37. Collins KK, Liu Y, Schootman M, Aft R, Yan Y, Dean G, et al. Effects of breast cancer surgery and surgical side effects on body image over time. Breast Cancer Res Treat (2011) 126(1):167-76. doi:10.1007/s10549-010-1077-7

38. Al-Ghazal SK, Fallowfield L, Blamey RW. Comparison of psychological aspects and patient satisfaction following breast conserving surgery, simple mastectomy and breast reconstruction. Eur J Cancer (2000) 36(15):1938-43. doi:10.1016/S0959-8049(00)00197-0

39. Rosenberg SM, Tamimi RM, Gelber S, Ruddy KJ, Kereakoglow S, Borges VF, et al. Body image in recently diagnosed young women with early breast cancer. Psychooncology (2013) 22(8):1849-55. doi:10.1002/pon.3221

40. Yurek D, Farrar W, Andersen BL. Breast cancer surgery: comparing surgical groups and determining individual differences in postoperative sexuality and body change stress. J Consult Clin Psychol (2000) 68(4):697-709. doi:10.1037/0022-006X.68.4.697

41. Cocquyt VF, Blondeel PN, Depypere HT, Van De Sijpe KA, Daems KK, Monstrey SJ, et al. Better cosmetic results and comparable quality of life after skin-sparing mastectomy and immediate autologous breast reconstruction compared to breast conservative treatment. Br J Plast Surg (2003) 56(5): 462-70. doi:10.1016/S0007-1226(03)00198-X

42. Fang SY, Shu BC, Chang YJ. The effect of breast reconstruction surgery on body image among women after mastectomy: a meta-analysis. Breast Cancer Res Treat (2013) 137(1):13-21. doi:10.1007/s10549-012-2349-1

43. Nicholson RM, Leinster S, Sassoon EM. A comparison of the cosmetic and psychological outcome of breast reconstruction, breast conserving surgery and mastectomy without reconstruction. Breast (2007) 16(4):396-410. doi:10.1016/j.breast.2007.01.009

44. Dian D, Schwenn K, Mylonas I, Janni W, Jaenicke F, Friese K. Aesthetic result among breast cancer patients undergoing autologous breast reconstruction versus breast conserving therapy. Arch Gynecol Obstet (2007) 275(6):445-50. doi:10.1007/s00404-006-0270-8

45. Morrow M, Li Y, Alderman AK, Jagsi R, Hamilton AS, Graff JJ, et al. Access to breast reconstruction after mastectomy and patient perspectives on reconstruction decision making. JAMA Surg (2014) 149(10):1015-21. doi:10.1001/ jamasurg.2014.548

46. Sisco M, Du H, Warner JP, Howard MA, Winchester DP, Yao K. Have we expanded the equitable delivery of postmastectomy breast reconstruction in the new millennium? Evidence from the national cancer data base. J Am Coll Surg (2012) 215(5):658-66. doi:10.1016/j.jamcollsurg.2012.07.008

47. Morrow M, Mujahid M, Lantz PM, Janz NK, Fagerlin A, Schwartz K, et al. Correlates of breast reconstruction: results from a population-based study. Cancer (2005) 104(11):2340-6. doi:10.1002/cncr.21444

48. Yang RL, Newman AS, Lin IC, Reinke CE, Karakousis GC, Czerniecki BJ, et al. Trends in immediate breast reconstruction across insurance groups after enactment of breast cancer legislation. Cancer (2013) 119(13):2462-8. doi:10.1002/cncr.28050

49. Enewold LR, McGlynn KA, Zahm SH, Poudrier J, Anderson WF, Shriver CD, et al. Breast reconstruction after mastectomy among department of defense beneficiaries by race. Cancer (2014) 120(19):3033-9. doi:10.1002/cncr.28806

50. Yao K, Stewart AK, Winchester DJ, Winchester DP. Trends in contralateral prophylactic mastectomy for unilateral cancer: a report from the National Cancer Data Base, 1998-2007. Ann Surg Oncol (2010) 17(10):2554-62. doi:10.1245/s10434-010-1091-3

51. Tuttle TM, Habermann EB, Grund EH, Morris TJ, Virnig BA. Increasing use of contralateral prophylactic mastectomy for breast cancer patients: a trend toward more aggressive surgical treatment. J Clin Oncol (2007) 25(33):5203-9. doi:10.1200/JCO.2007.12.3141

52. King TA, Sakr R, Patil S, Gurevich I, Stempel M, Sampson M, et al. Clinical management factors contribute to the decision for contralateral prophylactic mastectomy. J Clin Oncol (2011) 29(16):2158-64. doi:10.1200/ JCO.2010.29.4041

53. Yi M, Meric-Bernstam F, Middleton LP, Arun BK, Bedrosian I, Babiera GV, et al. Predictors of contralateral breast cancer in patients with unilateral breast cancer undergoing contralateral prophylactic mastectomy. Cancer (2009) 115(5):962-71. doi:10.1002/cncr.24129 
54. Nichols HB, de Gonzalez AB, Lacey JV, Rosenberg PS, Anderson WF. Declining incidence of contralateral breast cancer in the United States from 1975 to 2006. J Clin Oncol (2011) 29(12):1564-9. doi:10.1200/Jco.2010.32.7395

55. Gao X, Fisher SG, Emami B. Risk of second primary cancer in the contralateral breast in women treated for early-stage breast cancer: a population-based study. Int J Radiat Oncol (2003) 56(4):1038-45. doi:10.1016/S0360-3016(03)00203-7

56. Neta G, Anderson WF, Gilbert E, Berrington A. Variation in the risk of radiation-related contralateral breast cancer by histology and estrogen receptor expression in SEER. Breast Cancer Res $\operatorname{Tr}$ (2012) 131(3):1021-7. doi:10.1007/ s10549-011-1820-8

57. Bedrosian I, Hu CY, Chang GJ. Population-based study of contralateral prophylactic mastectomy and survival outcomes of breast cancer patients. J Natl Cancer Inst (2010) 102(6):401-9. doi:10.1093/jnci/djq018

58. Boughey JC, Hoskin TL, Degnim AC, Sellers TA, Johnson JL, Kasner MJ, et al. Contralateral prophylactic mastectomy is associated with a survival advantage in high-risk women with a personal history of breast cancer. Ann Surg Oncol (2010) 17(10):2702-9. doi:10.1245/s10434-010-1136-7

59. Kurian AW, Lichtensztajn DY, Keegan TH, Nelson DO, Clarke CA, Gomez SL. Use of and mortality after bilateral mastectomy compared with other surgical treatments for breast cancer in California, 1998-2011. JAMA (2014) 312(9):902-14. doi:10.1001/jama.2014.10707

60. Lostumbo L, Carbine NE, Wallace J. Prophylactic mastectomy for the prevention of breast cancer. Cochrane Database Syst Rev (2010) (11):CD002748. doi:10.1002/14651858.CD002748.pub3

61. Abbott A, Rueth N, Pappas-Varco S, Kuntz K, Kerr E, Tuttle T. Perceptions of contralateral breast cancer: an overestimation of risk. Ann Surg Oncol (2011) 18(11):3129-36. doi:10.1245/s10434-011-1914-x

62. Han E, Johnson N, Glissmeyer M, Wagie T, Carey B, DelaMelena T, et al. Increasing incidence of bilateral mastectomies: the patient perspective. Am J Surg (2011) 201(5):615-8. doi:10.1016/j.amjsurg.2011.01.018

63. Rosenberg SM, Tracy MS, Meyer ME, Sepucha K, Gelber S, HirshfieldBartek J, et al. Perceptions, knowledge, and satisfaction with contralateral prophylactic mastectomy among young women with breast cancer: a cross-sectional survey. Ann Intern Med (2013) 159(6):373-81. doi:10.7326/0003-4819-159-6-201309170-00003

64. Covelli AM, Baxter NN, Fitch MI, McCready DR, Wright FC. 'Taking control of cancer': understanding women's choice for mastectomy. Ann Surg Oncol (2015) 22(2):383-91. doi:10.1245/s10434-014-4033-7
65. Yao K, Belkora J, Sisco M, Rosenberg S, Bedrosian I, Liederbach E, et al. Survey of the deficits in surgeons' knowledge of contralateral prophylactic mastectomy. JAMA Surg (2015):1-3. doi:10.1001/jamasurg.2015.3601

66. Mavaddat N, Peock S, Frost D, Ellis S, Platte R, Fineberg E, et al. Cancer risks for BRCA1 and BRCA2 mutation carriers: results from prospective analysis of EMBRACE. J Natl Cancer Inst (2013) 105(11):812-22. doi:10.1093/jnci/ djt095

67. Meijers-Heijboer H, van Geel B, van Putten WL, Henzen-Logmans SC, Seynaeve C, Menke-Pluymers MB, et al. Breast cancer after prophylactic bilateral mastectomy in women with a BRCA1 or BRCA2 mutation. $N$ Engl $J$ Med (2001) 345(3):159-64. doi:10.1056/NEJM200107193450301

68. Metcalfe K, Gershman S, Lynch HT, Ghadirian P, Tung N, Kim-Sing C, et al. Predictors of contralateral breast cancer in BRCA1 and BRCA2 mutation carriers. Br J Cancer (2011) 104(9):1384-92. doi:10.1038/bjc.2011.120

69. van der Kolk DM, de Bock GH, Leegte BK, Schaapveld M, Mourits MJ, de Vries J, et al. Penetrance of breast cancer, ovarian cancer and contralateral breast cancer in BRCA1 and BRCA2 families: high cancer incidence at older age. Breast Cancer Res Treat (2010) 124(3):643-51. doi:10.1007/ s10549-010-0805-3

70. Reiner AS, John EM, Brooks JD, Lynch CF, Bernstein L, Mellemkjaer L, et al. Risk of asynchronous contralateral breast cancer in noncarriers of BRCA1 and BRCA2 mutations with a family history of breast cancer: a report from the Women's Environmental Cancer and Radiation Epidemiology Study. J Clin Oncol (2013) 31(4):433-9. doi:10.1200/JCO.2012.43.2013

71. Stuckey AR, Onstad MA. Hereditary breast cancer: an update on risk assessment and genetic testing in 2015. Am J Obstet Gynecol (2015) 213(2):161-5. doi:10.1016/j.ajog.2015.03.003

Conflict of Interest Statement: The authors declare that the research was conducted in the absence of any commercial or financial relationships that could be construed as a potential conflict of interest.

Copyright ( $\odot 2016$ Bellavance and Kesmodel. This is an open-access article distributed under the terms of the Creative Commons Attribution License (CC BY). The use, distribution or reproduction in other forums is permitted, provided the original author(s) or licensor are credited and that the original publication in this journal is cited, in accordance with accepted academic practice. No use, distribution or reproduction is permitted which does not comply with these terms. 